\title{
Morphological Changes in the Hippocampus Following Nicotine and Kainic Acid Administration
}

\author{
V. RILJAK, M. MILOTOVÁ, K. JANDOVÁ, J. POKORNÝ, M. LANGMEIER \\ Institute of Physiology, First Faculty of Medicine, Charles University, Prague, \\ Czech Republic
}

Received June 21, 2006

Accepted December 7, 2006

On-line available January 2, 2007

\begin{abstract}
Summary
Using histochemical analysis (NADPH-diaphorase, Fluoro-Jade B dye and bis-benzimide 33342 Hoechst) we studied the influence of intraperitoneal administration of nicotine (NIC), kainic acid (KA) and combination of both these substances on hippocampal neurons and their changes. In experiments, 35-day-old male rats of the Wistar strain were used. Animals were pretreated with $1 \mathrm{mg} / \mathrm{kg}$ of nicotine $30 \mathrm{~min}$ prior to the kainic acid application $(10 \mathrm{mg} / \mathrm{kg})$. After two days, the animals were transcardially perfused with $4 \%$ paraformaldehyde under deep thiopental anesthesia. Cryostat sections were stained to identify NADPH-diaphorase positive neurons that were then quantified in the CA1 and CA3 areas of the hippocampus, in the dorsal and ventral blades of the dentate gyrus and in the hilus of the dentate gyrus. Fluoro-Jade B positive cells were examined in the same areas in order to elucidate a possible neurodegeneration. In animals exposed only to nicotine the number of NADPH-diaphorase positive neurons in the CA3 area of the hippocampus and in the hilus of the dentate gyrus was higher than in controls. In contrast, KA administration lowered the number of NADPH-diaphorase positive cells in all studied hippocampal areas and in both blades of the dentate gyrus. Massive cell degeneration was observed in CA1 and CA3 areas of the hippocampus and in the hilus of the dentate gyrus after kainic acid administration. Animals exposed to kainic acid and pretreated with nicotine exhibited degeneration to a lesser extent and the number of NADPH-diaphorase positive cells was higher compared to rats, which were exposed to kainic acid only.
\end{abstract}

\section{Key words}

Kainic acid $\bullet$ Nitric oxide $\bullet$ Nicotine $\bullet$ Hippocampus $\bullet$ Neurodegeneration

\section{Introduction}

Nicotine, the main alkaloid found in tobacco, and its analogues exert a number of neurovegetative, behavioral and psychological effects on the central nervous system (CNS), which depend on the activation of specific cholinergic receptors (Benowitz 1986).
Cholinergic receptors can be divided into two types, muscarinic and nicotinic, based on the pharmacological action of various agonists and antagonists (James and Norberg 1995).

Nicotine has been reported to have a positive effect in patients with some neurodegenerative diseases (such as Alzheimer's and Parkinson's diseases) and 
nicotine has been suggested for the treatment of these CNS disorders (Ryan et al. 2001, James and Norberg 1995). Progression of these diseases is related to oxidative stress, resulting from either a decrease in antioxidant levels or an increase in reactive oxygen species or reactive nitrogen species. The role of nicotine in neurodegenerative disorders is still incompletely understood, because there is evidence that nicotine has both antioxidant and prooxidant effects (Newman et al. 2002).

Kainic acid (KA), the analogue of excitatory amino acid L-glutamate, interacts with specific receptors in the central nervous system. Systemic injection of KA causes severe convulsions, seizure-induced brain damage and increased seizure susceptibility in the rat (Ben-Ari 1985, Sperk 1994). These sequel closely resemble those of human temporal lobe epilepsy. Therefore, KA-induced epilepsy has become a widely accepted animal model for this and some other neurological disorders (Ben-Ari 1985, Nadler 1980).

Although many brain areas are affected by KA administration, the hippocampus seems to be one of the most influenced areas (Ben Ari et al. 1979a,b, Gottesfeld and Jacobowitz 1979, Kohler et al. 1979, Nadler et al. 1980, Sperk et al. 1983). The neurodegeneration of cells in the CA3 area of the hippocampus brings about epileptiform activity of the CA1 pyramidal cells, which is characterized by enhanced NMDA-mediated excitatory phase with apparent loss of GABA-mediated postsynaptic inhibition (Turner and Wheal 1991). Systemic kainic acid administration leads to neuronal degeneration, characterized among others by cell loss, when kainic acid is administered once or repeatedly (Riljak et al. 2005). The cell loss is not specific for kainic acid administration only but also for other neurotoxic insults (e.g. alcohol) (Milotová et al. 2005).

Nitric oxide $(\mathrm{NO})$ is produced from L-arginine by nitric oxide synthase (NOS). There are at least three different forms of that enzyme, the endothelial (eNOS) which is responsible for cardiovascular actions, the inducible one (iNOS) found originally in macrophages and involved mainly in immunological processes and a neuronal form (nNOS). Although all forms can be found in the CNS, the specific actions on neurotransmission may be attributed primarily to NO produced by nNOS located in neurons. Neuronal NOS is a constitutive enzyme, which is expressed only by a small percentage of neurons. Production of NO is a calmodulin-dependent process, which must be preceded by an elevation of intracellular $\mathrm{Ca}^{2+}$ concentration (Kiss 2000). $\mathrm{Ca}^{2+}$ influx is induced by activation of glutamate receptors, preferentially NMDA receptor (Prast and Philippu 2001).

Neuronal nitric oxide plays an important role in brain function. Studies conducted in the nineties suggested that NO mediates changes in cerebral blood flow not only under certain physiological (Iadecola 1993) but also under pathological conditions, such as KAinduced seizures (Rigaud-Monnet et al. 1994, 1995). There are only few studies which examined the possible modulation of KA-induced syndrome by nicotine. They indicate that nicotine pretreatment attenuates KA-induced neurodegeneration and that this alkaloid lowers the behavioral changes, which typically accompany KA application (Semba et al. 1996, Shytle et al. 1995). For example, Borlongan et al. (1995) reported that nicotine pretreatment blocks KA-induced wet dog shakes (WDS). The animals receiving nicotine before KA application displayed only mild limbic convulsions with sporadic incidents of head and jaw clonus. In contrast, animals receiving saline before KA administration displayed prominent convulsions accompanied by excessive salivation, severe convulsions and hyperkinesis in addition to consistent WDS (Borlongan et al. 1995).

Three main problems are concerned in this paper. First, whether and how can changes in the number of NADPH-diaphorase positive neurons induced by nicotine application and KA application influence brain structure of young rats. Second, if nicotine pre-treatment can modulate expression of KA-induced structural changes. Third, if nicotine has some degenerative potential in the CNS.

\section{Methods}

Male 35-day-old Wistar rats from our own breeding colony were used for the experiments. They were housed at a constant temperature $\left(23^{\circ} \mathrm{C}\right)$ and relative humidity $(60 \%)$ with a fixed $12 \mathrm{~h}$ light/dark cycle and fed with food and water ad libitum. Procedures involving animals and their care were conducted in conformity with the institutional guidelines that are in compliance with national and international laws and policies. There were 24 animals in all the experimental groups, six animals in each group:

1) 35-day-old animals exposed to nicotine ( $1 \mathrm{mg} / \mathrm{kg})$ i.p.

2) 35-day-old animals exposed to kainic acid $(10 \mathrm{mg} / \mathrm{kg}$ ) i.p. 

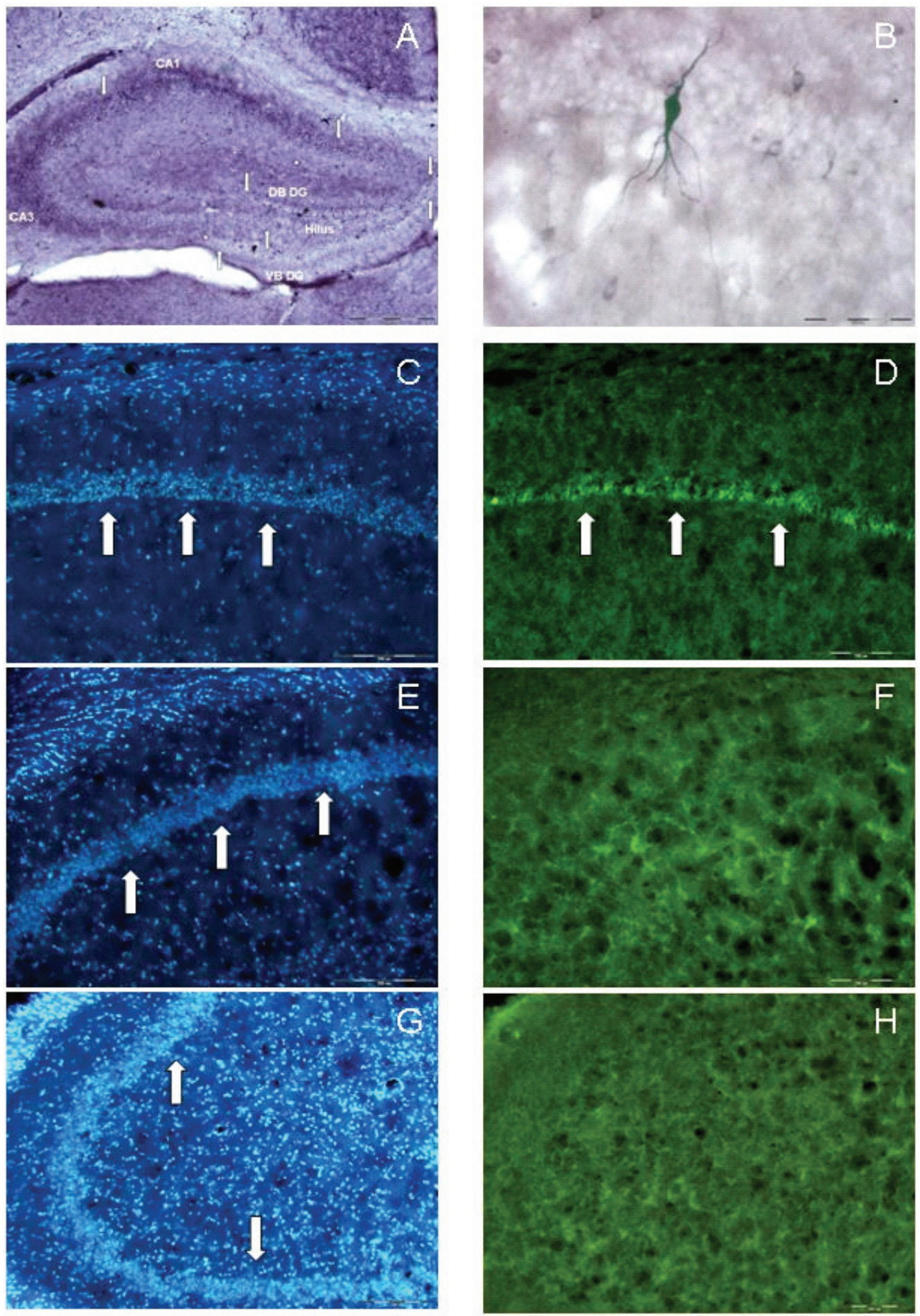

Fig. 1. Histological analyses of the hippocampus. A. Hippocampus (the arrows show the borders of investigated areas): CA1 and CA3 areas of the hippocampus, hilus of the dentate gyrus, DB DG - dorsal blade of the dentate gyrus, VB DG - ventral blades of the dentate gyrus. NADPH-diaphorase staining. Direct magnification 40x. B. NADPH-diaphorase positive cell in CA1 area of the hippocampus. Direct magnification 200x. C. CA1 area of the hippocampus (arrows). Bis-benzimide, Hoechst 33342 staining. Kainic acid-treated rat $(10 \mathrm{mg} / \mathrm{kg})$. Direct magnification 100x. D. CA1 area of the hippocampus (arrows show degenerating cells). Fluoro-Jade B staining. Kainic acid-treated rat $(10 \mathrm{mg} / \mathrm{kg}$ ). Direct magnification 100x. E. CA1 area of the hippocampus (arrows). Bis-benzimide, Hoechst 33342 staining. Nicotine treated rat $(1 \mathrm{mg} / \mathrm{kg}) 30 \mathrm{~min}$ prior kainic acid administration $(10 \mathrm{mg} / \mathrm{kg})$. Direct magnification 100x. F. CA1 area of the hippocampus. Fluoro-Jade B staining. Nicotine-treated rat $(1 \mathrm{mg} / \mathrm{kg}) 30 \mathrm{~min}$ prior kainic acid administration $(10 \mathrm{mg} / \mathrm{kg})$. Direct magnification 100x. G. CA1 and CA3 areas of the hippocampus (arrows). Bis-benzimide, Hoechst 33342 staining. Nicotine-treated rat $(1 \mathrm{mg} / \mathrm{kg}) 30 \mathrm{~min}$ prior kainic acid administration $(10 \mathrm{mg} / \mathrm{kg})$. Direct magnification 100x. H. CA1 and CA3 areas of the hippocampus. Fluoro-Jade B staining. Nicotine-treated rat $(1 \mathrm{mg} / \mathrm{kg}) 30$ min prior kainic acid administration $(10 \mathrm{mg} / \mathrm{kg})$. Direct magnification $100 \mathrm{x}$. 

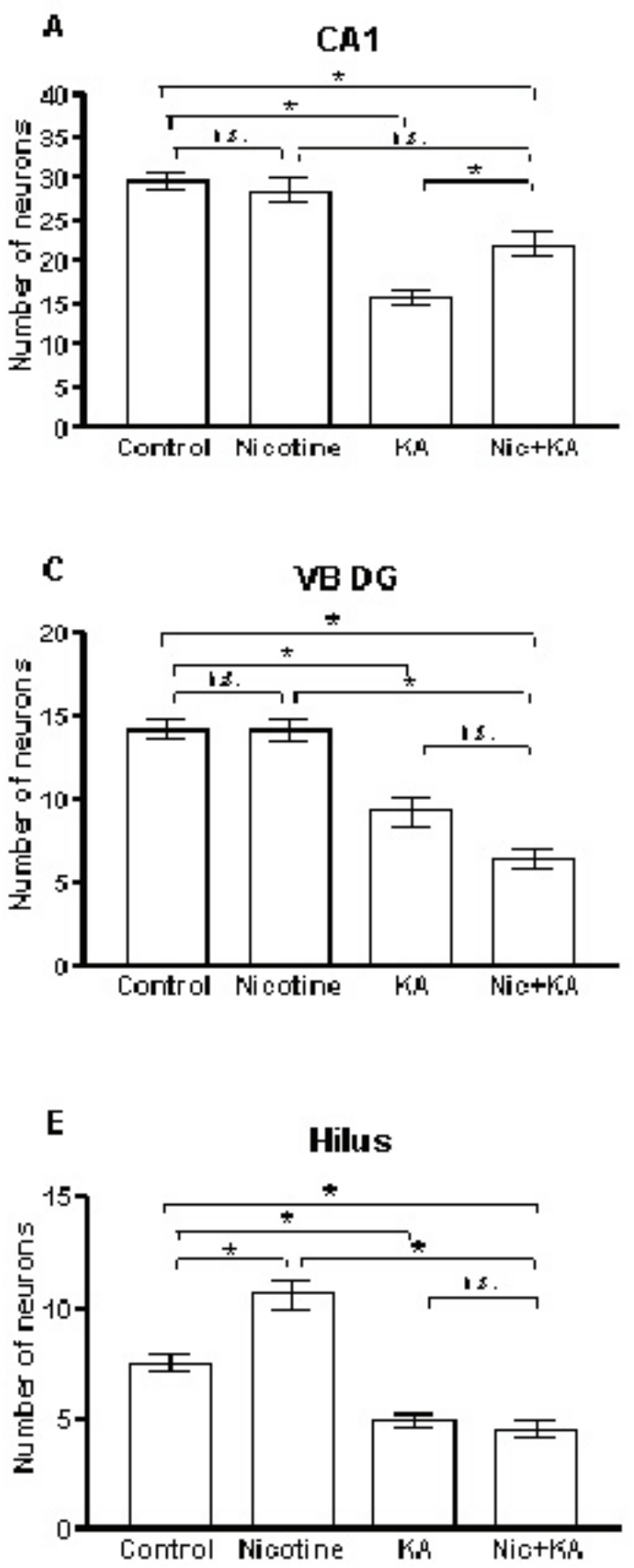

3) 35-day-old animals exposed to nicotine $(1 \mathrm{mg} / \mathrm{kg})$, followed in $30 \mathrm{~min}$ by KA i.p. injection $(10 \mathrm{mg} / \mathrm{kg})$

4) control 35-day-old animals exposed to normal saline in equal doses

Four brains of animals in each group were stained by NADPH-diaphorase method and 2 brains in each group were stained by combination of Fluoro-Jade B and Hoechst staining. In each brain 25-30 sections were examined and quantified. At the age of 35 days, animals received single intraperitoneal injection of nicotine, kainic acid or both substances. Animals of the control
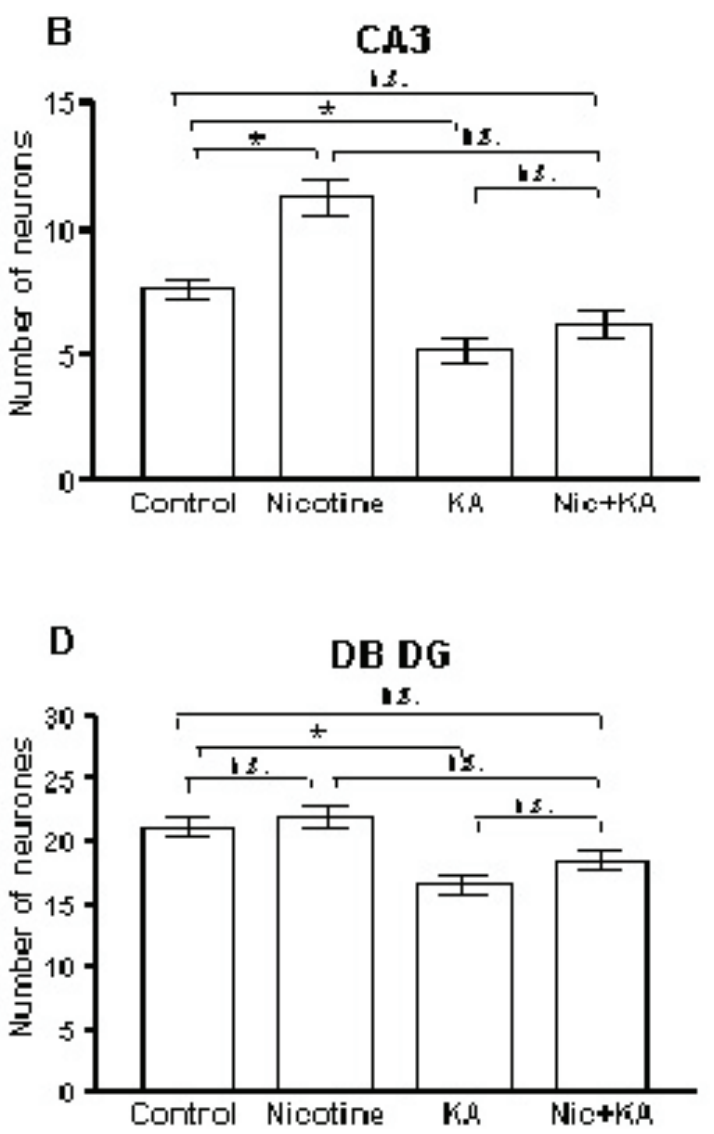

Fig. 2. A. Number of NADPH-diaphorase positive neurons in CA1 area of hippocampus per section area, B. Number of NADPHdiaphorase positive neurons in $\mathrm{CA} 3$ area of hippocampus per section area, $\mathbf{C}$. Number of NADPH-diaphorase positive neurons in ventral blade of the dentate gyrus per section area, D. Number of NADPH-diaphorase positive neurons in dorsal blade of the dentate gyrus per section area, E. Number of NADPH-diaphorase positive neurons in hilus of the dentate gyrus per section area; control group, nicotine-treated group, $\mathrm{KA}=$ kainic acid-treated group, Nic+KA = nicotine and kainic acid-treated group. Mean \pm S.E.M. * Significant difference $(p<0.001)$.

group received normal saline in equal volumes. Two days later, all animals were perfused under deep thiopental anaesthesia with $4 \%$ paraformaldehyde in $0.1 \mathrm{M}$ phosphate buffer at $\mathrm{pH}$ 7.4. Brains were removed, postfixed for one hour in $4 \%$ buffered paraformaldehyde and then submerged for $1 \mathrm{~h}$ into $20 \%$ sucrose for cryoprotection. Each brain was sliced in the frontal plane into $40 \mu \mathrm{m}$ thick sections with a cryostat. Then two different histochemical methods were used: 


\section{NADPH-diaphorase staining}

For the NADPH-diphorase examination the freefloating sections were placed in $0.1 \mathrm{M}$ phosphate buffer and incubated in $0.1 \mathrm{M}$ phosphate buffer containing $0.5 \mathrm{mg} / \mathrm{ml} \quad \beta$-NADPH (Sigma), $0.2 \mathrm{mg} / \mathrm{ml}$ Nitro blue tetrazolium (NBT, Sigma) and $0.3 \%$ Triton (Sigma) for $4 \mathrm{~h}$ at $37{ }^{\circ} \mathrm{C}$ in thermostat. Following the reaction, sections were rinsed in $0.1 \mathrm{M}$ phosphate buffer and kept at $8{ }^{\circ} \mathrm{C}$ for $16 \mathrm{~h}$. The histochemically reacted sections were mounted on precleaned $0.5 \%$ gelatine-coated microscope slides (Menzel-Gläser), air-dried and cover slipped with microscope cover glasses (Menzel-Gläser) using D.P.X. neutral mounting medium (Aldrich) (Wang et al. 2001). NADPH-diphorase positive neurons were then quantified in five regions of the hippocampal formation (each section was d evaluated) (Fig. 1):

1) CA1 area of the hippocampus,

2) CA3 area of the hippocampus,

3) the hilus of the dentate gyrus,

4) the dorsal blade of the dentate gyrus,

5) the ventral blade of the dentate gyrus

Hippocampus between the AP plane $2.5 \mathrm{~mm}$ and $4.0 \mathrm{~mm}$ posterior to the bregma was subjected to quantification of NADPH-diphorase positive neurons under the light microscope Olympus Provis AX 70 with epifluorescence illumination. For the statistical evaluation, ANOVA and the unpaired t-test (GraphPadPrism) were used (level of significance was set at $\mathrm{p}<0.001)$.

Combination of Fluoro-Jade B and bis-benzimide 33342 Hoechst

Fluoro-Jade B (FJB, Histo-Chem Inc.) is an anionic fluorescein derivative useful for the histological staining of neurons undergoing degeneration (Schmued and Hopkins 2000). Hoechst 33342 (Sigma) staining was used as an apoptotic marker, which detects apoptotic nuclei with condensed and/or fragmented DNA.

After cryostat sectioning, free-floating slices were placed in $0.1 \mathrm{M}$ phosphate buffer. Tissue sections were then mounted onto gelatinized slides and allowed to dry at room temperature. Slides were then placed in staining racks (one slide/slot for even staining) and immersed in $100 \%$ ethanol solution for $3 \mathrm{~min}$, in $70 \%$ ethanol solution for $1 \mathrm{~min}$, in distilled water for $1 \mathrm{~min}$, in $0.01 \%$ potassium permanganate $\left(\mathrm{KMnO}_{4}\right)$ (Sigma) for $15 \mathrm{~min}$ with gentle shaking. Slides were washed in distilled water three times. Staining proceeded in a dim place by immersing slides into $0.001 \%$ Fluoro-Jade B solution for $30 \mathrm{~min}$ with occasional gentle shaking (Schmued and Hopkins 2000). Thereafter the slides were rinsed in the distilled water three times for $1 \mathrm{~min}$. Slides were then immersed in $0.01 \%$ Hoechst staining solution for $10 \mathrm{~min}$ and dehydrated (in ethanol series), coverslipped using D.P.X. neutral mounting medium and allowed to dry. Fluoro-Jade B positive neurons were studied in the same hippocampal regions as those used for NADPH-diphorase evaluation (each section was evaluated). The tissue was examined using an epifluorescent microscope with blue (450-490 nm) excitation light. For the semiquantitative analysis, Fluoro-Jade B positive cells were counted by two independent workers in all slices. Each area of the hippocampus in the slice was evaluated by the scale: $(0)$ no FJB positive cells in field of view, $(+)$ sporadically present FJB cells in field of view, $(++)$ groups of FJB positive cells in field of view $(+++)$ massive alteration, the study area is completely undergoing degeneration.

\section{Results}

The results clearly show that the nicotine administration increased the number of NADPHdiphorase positive neurons in the hilus of the dentate gyrus and CA3 area of the hippocampus, compared to the control group (Fig. 2B, E). In other areas the difference from controls was not significant (Fig. 2A, C, D). KA given to the animals decreased the number of NADPHdiphorase positive neurons in all examined areas of the hippocampus (Fig. 2). The combination of both of these substances decreased the number of NADPH-diphorase positive neurons in the CA1 area of the hippocampus, compared to the control group, but the number of NADPH-diphorase positive cells was significantly higher when compared with only KA-exposed rats (Fig. 2A). Fluoro-Jade $\mathrm{B}$ staining revealed the massive neurodegeneration after KA application (Fig. 1C, D). The most affected regions were CA3 and CA1 areas of the hippocampus and hilus of the dentate gyrus. Both blades of the dentate gyrus remained intact. This confirmed the previous finding of other authors (French et al. 1982, de Montigny and Tardif 1981). Semiquantitative analysis showed that nicotine pretreatment before KA administration lowered the number of Fluoro-Jade B positive cells compared to rats, which were pretreated by KA only (Fig. 1E, F, G, H). This finding was especially prominent in CA1 and CA3 area of the hippocampus and in the hillus of the dentate gyrus (Table 1). Nicotine 
Table 1. Semiquantitative analyze of Fluoro-Jade B positive cells in experimental groups: control rats received equal dose of normal saline, kainic acid-treated rats $(10 \mathrm{mg} / \mathrm{kg})$, nicotine-treated rats $(1 \mathrm{mg} / \mathrm{kg})$, and rats pretreated with nicotine $(1 \mathrm{mg} / \mathrm{kg}) 30 \mathrm{~min}$ prior to kainic acid administration $(10 \mathrm{mg} / \mathrm{kg})$.

\begin{tabular}{lcrcr}
\hline Area & $\begin{array}{c}\text { Control } \\
\mathbf{n}=\mathbf{1 0 8}\end{array}$ & $\begin{array}{c}\text { Kainic acid } \\
\mathbf{n}=\mathbf{1 0 9}\end{array}$ & $\begin{array}{c}\text { Nicotine } \\
\mathbf{n = 1 1 2}\end{array}$ & $\begin{array}{c}\text { Nicotine }+ \\
\text { kainic acid } \\
\mathbf{n}=\mathbf{1 1 2}\end{array}$ \\
\hline CA1 & $29.80 \pm 0.97$ & $15.73 \pm 0.90$ & $28.59 \pm 1.43$ & $22.12 \pm 1.40$ \\
CA3 & $7.62 \pm 0.36$ & $5.20 \pm 0.46$ & $11.26 \pm 0.74$ & $6.22 \pm 0.53$ \\
Hilus & $7.50 \pm 0.37$ & $4.97 \pm 0.31$ & $10.62 \pm 0.63$ & $4.556 \pm 0.41$ \\
Ventral blade of dentate gyrus & $14.27 \pm 0.56$ & $9.36 \pm 0.88$ & $14.27 \pm 0.67$ & $6.50 \pm 0.67$ \\
Dorsal blade of dentate gyrus & $21.33 \pm 0.74$ & $16.58 \pm 0.68$ & $22.03 \pm 0.90$ & $18.56 \pm 0.83$ \\
\hline
\end{tabular}

Data are means \pm S.E.M. Each area of the hippocampus in the slice was evaluated by the scale: $(0)$ no FJB positive cells in field of view, $(+)$ sporadically present FJB cells in field of view, $(++)$ groups of FJB positive cells in field of view $(+++)$ massive alteration, the study area is completely undergoing degeneration.

administration produced no degeneration in any area of the hippocampus, albeit this dose $(1 \mathrm{mg} / \mathrm{kg})$ was rather high. Morphological analysis, using Hoechst 33342, confirmed that KA administration caused neuronal morphological changes (condensed nuclei, apoptotic bodies), reflecting apoptosis in the pyramidal layer of the hippocampal formation. No morphological signs of apoptosis (evaluated by Hoechst 33342) were found in animals receiving nicotine before $\mathrm{KA}$ administration.

\section{Discussion}

Systemic administration of KA in rats readily produces various motor signs including convulsive seizures (Ben-Ari 1985) and massive neuronal damage can be observed in the hippocampal formation (Sperk 1994, Riljak et al. 2005). We have confirmed that intraperitoneal administration of KA brought about death of neurons in the CA1 and CA3 areas of the hippocampus and in the hilus of the dentate gyrus. Mechanisms contributing to KA-induced seizures and brain damage are still not completely clear. The main causes are socalled axon sparing lesions, lesions mediated through activation of excitatory pathways, non-selective seizurerelated brain damage, changes in the blood-brain barrier and possibly some other (Sperk 1994). One cause of the high sensitivity of $\mathrm{CA} 1$ and $\mathrm{CA} 3$ areas of the hippocampus can be the high concentration of KA receptors upon the neurons of this structure (Sawada et al. 1988, Yoshihara et al. 2003).

When the character of neuronal injury is concerned, two major forms of morphologically distinct cell death have been observed under various neuropathologic conditions necrosis and apoptosis (Johnson and Deckwerth 1993, Nicotera and Lipton 1999). It is often difficult to decide whether the cell died by the necrotic or apoptotic process (Columbano 1995). The mechanism of neuronal death in the hippocampus, demonstrated in our experiments, is most likely apoptotic. But the necrotic process in the hippocampus cannot be excluded without any other histological method.

When the rats were pretreated by nicotine, neuronal degeneration was attenuated. This observation was confirmed by Fluoro-Jade B staining. Hoechst 33342 staining allowed to identify the cells with condensed, fragmented nuclei, which both have been proposed to be signs of apoptosis. To decide if the neurons are dying by apoptotic process must be confirmed by other methods.

It has been proposed that nicotine in the CNS has antioxidant properties. This aspect was extensively reviewed (Newman et al. 2002). Nicotine might also act as an antioxidant and/or it can inhibit complex I of the electron transport chain, with a consequent reduction in the levels of reactive oxygen species (Cormier et al. 2003, Newman et al. 2002, Obata et al. 2002, Soto-Otero et al. 2002). Increased nicotine-induced expression of neurotrophic factors crucial for neuronal maintenance, survival and regeneration has also been discussed (Matarredona et al. 2001, Roceri et al. 2001).

In our experiments, kainic acid administration decreased the number of NADPH-diaphorase positive neurons. It can be the result of kainic acid-induced neurodegeneration in the hippocampal area, or it is a 
consequence of kainic acid application that decreases the number of all neurons and the NADPH-diaphorase positive neurons are not excluded. It has been proposed that some other insults (for example perinatal long-lasting hypobaric hypoxia) result in a decreased number of NADPH-diaphorase positive neurons (Benešová et al. 2005, Marešová et al. 2005, Jandová et al. 2006). Considering, that the dose of kainic acid used in our experiment reached the convulsive limit, the cell loss was not surprising. Some authors, who studied the effects of subconvulsive doses of the kainic acid, did not find any structural changes in the hippocampus (Koryntová et al. 1997). Our prediction must be confirmed in future studies, which will quantify the whole neuronal population.

In this and our previous experiments the nicotine administration was associated with higher numbers of NADPH-diaphorase positive neurons in CA3 area of the hippocampus and hilus of the dentate gyrus in comparison with either group of control animals (Riljak et al. 2006). NADPH-diaphorase positive neurons were repeatedly reported to be relatively resistant to the injury caused by status epilepticus (Koh et al. 1986, LernerNatoli et al. 1994), but the findings related to vulnerability or survival of this neuronal population after status epilepticus are still controversial. If such speculations are true, increased number of the NADPHdiaphorase positive cells following nicotine application may act as a protective factor against excitotoxin-induced degeneration. On the other hand, it has been demonstrated that NO (free radical synthesized by NOsynthase which is colocalized with NADPH-diaphorase) and superoxide radicals combine to produce peroxynitrite that spontaneously decomposes forming hydroxyl radicals and nitrogen dioxide, which can produce cell damage (Ischiropoulos et al. 1992). The role of NO in the CNS is still not fully understood and many questions remain to be elucidated.

\section{Acknowledgements}

This work was supported by grants GAČR 305/03/H148, GAČR 309/05/2015 and MSM 0021620816. We thank M. Vopavová and A. Burianová for excellent technical assistance.

\section{References}

BEN ARI Y: Limbic seizure and brain damage produced by kainic acid: mechanisms and relevance to human temporal lobe epilepsy. Neuroscience 14: 375-403, 1985.

BEN ARI Y, LAGOWSKA J, TREMBLAY E, LE GAL LS: A new model of focal status epilepticus: intra-amygdaloid application of kainic acid elicits repetitive secondarily generalized convulsive seizures. Brain Res 163: 176179, 1979a.

BEN ARI Y, TREMBLAY E, OTTERSEN OP, NAQUET R: Evidence suggesting secondary epileptogenic lesion after kainic acid: pretreatment with diazepam reduces distant but not local brain damage. Brain Res 165: 362-365, 1979b.

BENEŠOVÁ P, LANGMEIER M, BETKA J, TROJAN S: Long-lasting changes in the density of nitrergic neurons following kainic acid administration and chronic hypoxia. Physiol Res 54: 565-571, 2005.

BENOWITZ NL: Clinical pharmacology of nicotine. Annu Rev Med 37: 21-32, 1986.

BORLONGAN CV, SHYTLE RD, ROSS SD, SHIMIZU T, FREEMAN TB, CAHILL DW, SANBERG PR: (-)-nicotine protects against systemic kainic acid-induced excitotoxic effects. Exp Neurol 136: 261-265, 1995.

COLUMBANO A: Cell death: current difficulties in discriminating apoptosis from necrosis in the context of pathological processes in vivo. J Cell Biochem 58: 181-190, 1995.

CORMIER A, MORIN C, ZINI R, TILLEMENT JP, LAGRUE G: Nicotine protects rat brain mitochondria against experimental injuries. Neuropharmacology 44: 642-652, 2003.

DE MONTIGNY C, TARDIF D: Differential excitatory effects of kainic acid on CA3 and CA1 hippocampal pyramidal neurons: further evidence for the excitotoxic hypothesis and for a receptor-mediated action. Life Sci 29: 2103$2111,1981$.

FRENCH ED, ALDINIO C, SCHWARCZ R: Intrahippocampal kainic acid, seizures and local neuronal degeneration: relationships assessed in unanesthetized rats. Neuroscience 7: 2525-2536, 1982.

GOTTESFELD Z, JACOBOWITZ DM: Kainic acid-induced neurotoxicity in the striatum: a histofluorescent study. Brain Res 169: 513-518, 1979. 
IADECOLA C: Regulation of the cerebral microcirculation during neural activity: is nitric oxide the missing link? Trends Neurosci 16: 206-214, 1993.

ISCHIROPOULOS H, ZHU L, CHEN J, TSAI M, MARTIN JC, SMITH CD, BECKMAN JS: Peroxynitrite-mediated tyrosine nitration catalyzed by superoxide dismutase. Arch Biochem Biophys 298: 431-437, 1992.

JAMES JR, NORDBERG A: Genetic and environmental aspects of the role of nicotinic receptors in neurodegenerative disorders: emphasis on Alzheimer's disease and Parkinson's disease. Behav Genet 25: 149-159, 1995.

JANDOVÁ K, LANGMEIER M, MAREŠOVÁ D, POKORNÝ J, TROJAN S: Effect of magnesium pre-treatment on the hippocampal NOS activity during long-lasting intermittent hypoxia. Prague Med Rep 107: 108-116, 2006.

JOHNSON EM, DECKWERTH TL: Molecular mechanism of developmental neuronal death. Annu Rev Neurosci 16: 31-46, 1993.

KISS JP: Role of nitric oxide in the regulation of monoaminergic neurotransmission. Brain Res Bull 52: 459-466, 2000.

$\mathrm{KOH}$ JY, PETERS S, CHOI DW: Neurons containing NADPH-diaphorase are selectively resistant to quinolinate toxicity. Science 234: 73-76, 1986.

KOHLER C, SCHWARCZ R, FUXE K: Hippocampal lesions indicate differences between the excitotoxic properties of acidic amino acids. Brain Res 175: 366-371, 1979.

KORYNTOVÁ H, ŠLAPAL R, LANGMEIER M, HAUGVICOVÁ R, MAREŠ P: Effects of a subconvulsant dose of kainic acid on afterdischarges elicited by cortical stimulation in rats. Epilepsy Res 29: 25-33, 1997.

LERNER-NATOLI M, DE BOCK F, BOCKAERT J, RONDOUIN G: NADPH diaphorase-positive cells in the brain after status epilepticus. Neuroreport 5: 2633-2637, 1994.

MAREŠOVÁ D, JANDOVÁ K, BORTELOVÁ J, TROJAN S, TRNKOVÁ B: Functional and morphological changes of the brain in rats exposed to intermittent hypobaric hypoxia after the repetitive magnesium administration. Prague Med Rep 106: 61-69, 2005.

MATARREDONA ER, SANTIAGO M, VENERO JL, CANO J, MACHADO A: Group II metabotropic glutamate receptor activation protects striatal dopaminergic nerve terminals against MPP+-induced neurotoxicity along with brain-derived neurotrophic factor induction. J Neurochem 76: 351-360, 2001.

MILOTOVÁ M, RILJAK V, LANGMEIER M, MAREŠOVÁ D, JANDOVÁ K, POKORNÝ J, TROJAN S: Effect of the perinatal alcohol abuse on the development of neuronal population in the hippocampus. Prague Med Rep 106: 71-74, 2005.

NADLER JV, PERRY BW, GENTRY C, COTMAN CW: Degeneration of hippocampal CA3 pyramidal cells induced by intraventricular kainic acid. J Comp Neurol 192: 333-359, 1980.

NEWMAN MB, ARENDASH GW, SHYTLE RD, BICKFORD PC, TIGHE T, SANBERG PR: Nicotine's oxidative and antioxidant properties in CNS. Life Sci 71: 2807-2820, 2002.

NICOTERA R, LIPTON SA: Excitotoxins in neuronal apoptosis and necrosis. J Cereb Blood Flow Metab 19: 583-591, 1999.

OBATA T, AOMINE M, INADA T, KINEMUCHI H: Nicotine suppresses 1-methyl-4-phenylpyridinium ion-induced hydroxyl radical generation in rat striatum. Neurosci Lett 330: 122-124, 2002.

PRAST H, PHILIPPU A: Nitric oxide as modulator of neuronal function. Prog Neurobiol 64: 51-68, 2001.

RIGAUD-MONNET AS, HERON A, SEYLAZ J, PINARD E: Effect of inhibiting NO synthesis on hippocampal extracellular glutamate concentration in seizures induced by kainic acid. Brain Res 673: 297-303, 1995.

RIGAUD-MONNET AS, PINARD E, BORREDON J, SEYLAZ J: Blockade of nitric oxide synthesis inhibits hippocampal hyperemia in kainic acid-induced seizures. J Cereb Blood Flow Metab 14: 581-590, 1994.

RILJAK V, MILOTOVÁ M, JANDOVÁ K, LANGMEIER M, MAREŠOVÁ D, POKORNÝ J, TROJAN S: Repeated kainic acid administration and hippocampal neuronal degeneration. Prague Med Rep 106: 75-78, 2005.

RILJAK V, MILOTOVÁ M, JANDOVÁ K, MAREŠOVÁ D, POKORNÝ J, TROJAN S, LANGMEIER M: Changes in the number of nitrergic neurons in rats hippocampus following nicotine administration. Prague Med Rep 107: 117-124, 2006.

ROCERI M, MOLTENI R, FUMAGALLI F, RACAGNI G, GENNARELLI M, CORSINI G, MAGGIO R, RIVA M: Stimulatory role of dopamine on fibroblast growth factor-2 expression in rat striatum. J Neurochem 76: 990997, 2001. 
RYAN RE, ROSS SA, DRAGO J, LOIACONO RE: Dose-related neuroprotective effects of chronic nicotine in 6-hydroxydopamine treated rats, and loss of neuroprotection in alpha4 nicotinic receptor subunit knockout mice. Br J Pharmacol 132: 1650-1656, 2001.

SAWADA S, HIGASHIMA M, YAMAMOTO C: Kainic acid induces long-lasting depolarizations in hippocampal neurons only when applied to stratum lucidum. Exp Brain Res 72: 135-140, 1988.

SCHMUED LC, HOPKINS KJ: Fluoro-Jade B: a high affinity fluorescent marker for the localization of neuronal degeneration. Brain Res 874: 123-130, 2000.

SEMBA J, MIYOSHI R, KITO S: Nicotine protects against the dexamethasone potentiation of kainic acid-induced neurotoxicity in cultured hippocampal neurons. Brain Res 735: 335-338, 1996.

SHYTLE RD, BORLONGAN CV, SANBERG PR: Nicotine blocks kainic acid-induced wet dog shakes in rats. Neuropsychopharmacol 13: 261-264, 1995.

SOTO-OTERO R, MENDEZ-ALVAREZ E, HERMIDA-AMEIJEIRAS A, LOPEZ-REAL AM, LABANDEIRAGARCIA JL: Effects of (-)-nicotine and (-)-cotinine on 6-hydroxydopamine-induced oxidative stress and neurotoxicity: relevance for Parkinson's disease. Biochem Pharmacol 64: 125-135, 2002.

SPERK G: Kainic acid seizures in the rat. Prog Neurobiol 42: 1-32, 1994.

SPERK G, LASSMANN H, BARAN H, KISH SJ, SEITELBERGER F, HORNYKIEWICZ O: Kainic acid induced seizures: neurochemical and histopathological changes. Neuroscience 10: 1301-1315, 1983.

TURNER DA, WHEAL HV: Excitatory synaptic potentials in kainic acid-denervated rat CA1 pyramidal neurons. J Neurosci 11: 2786-2794, 1991.

WANG TJ, LUE JH, SHIEH JY, WEN CY: The distribution and characterization of NADPH-d/NOS-IR neurons in the rat cuneate nucleus. Brain Res 910: 38-48, 2001.

YOSHIHARA Y, ONODERA H, IINUMA K, ITOYAMA Y: Abnormal kainic acid receptor density and reduced seizure susceptibility in dystrophin-deficient mdx mice. Neuroscience 117: 391-395, 2003.

\section{Corresponding author}

Vladimír Riljak, Institute of Physiology, First Faculty of Medicine, Charles University, Albertov 5, 12800 Prague 2, Czech Republic. Fax: +420 224918816. E-mail: vladimir.riljak@lf1.cuni.cz 